\title{
Bixaceae do Estado do Paraná, Brasil
}

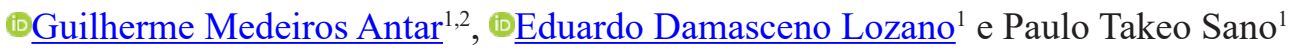

Recebido: 10 junho 2019; aceito: 5 dezembro 2019

Como citar: Antar, G.M., Lozano, E.D. \& Sano, P.T. 2020. Bixaceae do Estado do Paraná, Brasil. Hoehnea 47: e672019. http://dx.doi.org/10.1590/2236-8906-67/2019.

ABSTRACT - (Bixaceae of the Paraná State, Brazil). This study provides a floristic survey of the Bixaceae from Paraná State. The family is represented in the area by two species: Cochlospermum regium (Mart. ex Schrank) Pilg., native from the remnants of the Cerrado biome, and Bixa orellana L., which has an uncertain origin but occurs sub-spontaneously in Paraná State. Descriptions, an identification key, photographs, and comments on the taxonomy of these species are provided. Keywords: Bixa, Cerrado, Cochlospermaceae, Cochlospermum, flora

RESUMO - (Bixaceae do Estado do Paraná, Brasil). Este trabalho apresenta o tratamento florístico de Bixaceae para o Estado do Paraná. A família está representada por duas espécies: Cochlospermum regium (Mart. ex Schrank) Pilg., nativa dos remanescentes de Cerrado; e Bixa orellana L., de origem incerta, mas subespontânea no Estado do Paraná. São apresentadas descrições, uma chave de identificação para as espécies, pranchas fotográficas e comentários taxonômicos.

Palavras-chave: Bixa, Cerrado, Cochlospermaceae, Cochlospermum, flora

\section{Introdução}

Bixaceae Kunth possui distribuição pantropical, sendo mais diversa nos Neotrópicos (Stevens 2019). É composta por cerca de 21 espécies, reunidas em quatro gêneros: Amoreuxia Moç. \& Sessé, Bixa L., Cochlospermum Kunth e Diegodendron Capuron (Heald 2004, Poppendieck 2002a, 2002b, Stevens 2019). A família está presente em regiões com climas majoritariamente sazonais, habitando formações florestais decíduas e semi-decíduas, florestas tropicais, ambientes campestres e savanas (Bayer 2002, Poppendieck 1981, 2002a, 2002b).

Tradicionalmente, Bixaceae era reconhecida apenas pelo gênero monotípico Bixa; porém, estudos baseados em caracteres moleculares sustentam a circunscrição de outros três gêneros em Bixaceae (APG IV 2016, Fay et al. 1988), que anteriormente eram reconhecidos em outras duas famílias distintas: Amourexia e Cochlospermum (Cochlospermaceae Planchon) e Diegodendron (Diegodendraceae Capuron) (Bayer 2002, Poppendieck 2002a, 2002b). Estudos filogenéticos recentes (Johnson-Fulton \& Watson 2017) apontam uma nova separação de Cochlospermaceae de Bixaceae (circunscrita com Bixa e Diegodendron), com base na fraca sustentação de Bixaceae s.l. e nas significativas diferenças morfológicas entre os gêneros. Para que essa situação seja esclarecida, novos estudos filogenéticos com esses táxons são necessários (Johnson-Fulton \& Watson 2017).

Estudos florísticos regionais têm sido conduzidos com a família no Brasil (e.g. Kirazawa 2002, Antar \& Sano 2016, Fernandes-Júnior \& Gil 2017, Ribeiro \& Loiola 2017), a qual apresenta seis espécies no país, sendo três pertencentes a Bixa e três a Cochlospermum (Antar 2019). No Estado do Paraná, Bixaceae está representada por duas espécies, Bixa orellana e Cochlospermum regium, ambas tratadas neste estudo.

\section{Material e métodos}

Localizado na região Sul do Brasil, o Paraná possui uma área de ca. $200 \mathrm{mil} \mathrm{km} \mathrm{km}^{2}$, sendo recoberto pelos domínios da Mata Atlântica e do Cerrado (IBGE 2004). De acordo com a classificação de Köppen (1900), o Estado está sob influência dos tipos climáticos $\mathrm{Cfa}$ (subtropical com verões quentes) e $\mathrm{Cfb}$ (temperado com verões frescos) (Alvares et al. 2013).

1. Universidade de São Paulo, Instituto de Biociências, Departamento de Botânica, Rua do Matão 277, 05508-090 São Paulo, SP, Brasil

2. Autor para correspondência: guilherme.antar@gmail.com 
Quanto ao material botânico, foram consultados os acervos dos herbários: HCF, K, MBM, RB, SP, SPF e UPCB (acrônimos segundo Thiers, continuamente atualizado). A terminologia morfológica empregada segue Hickey (1973), para morfologia foliar; Harris \&
Harris (2001), para morfologia geral; além de literatura específica: Baer (1974) para Bixa e Poppendieck (1981) para Cochlospermum. Os mapas de distribuição foram produzidos com o programa QGIS versão 2.18.20 (QGIS Development Team 2019).

\section{Resultados e Discussão}

\section{Chave para as espécies de Bixaceae no Paraná}

1. Árvores a arvoretas; folhas inteiras, indumento com tricomas peltados; corola rosada; ovário bicarpelar; frutos bivalvares; sementes carnosas, turbinadas, glabras 1. Bixa orellana

1. Arbustos; folhas palmatilobadas, indumento com tricomas simples; corola amarelada; ovário 3-5 carpelar; frutos 3-5 valvares; sementes não carnosas, reniformes, lanosas 2. Cochlospermum regium

Tratamento florístico

\section{Bixa L.}

Árvores até 30 metros de altura, arvoretas ou arbustos, exsudato alaranjado ou avermelhado presente, indumento de ramos jovens, folhas e frutos de tricomas peltados; par de nectários extraflorais presentes nos nós foliares. Folhas simples, inteiras, perenes, membranáceas ou raramente coriáceas, margem inteira; pecíolos longos, pulvinados no ápice e na base; estípulas lineares, cedo caducas. Inflorescências paniculares, terminais; brácteas caducas presentes nas ramificações da inflorescência, deixando cicatrizes transversais, nectário extrafloral 1, disposto abaixo da cicatriz das brácteas. Flores actinomorfas; pedicelo com cinco nectários extraflorais dispostos abaixo do cálice, conspícuos, inconspícuos ou raramente ausentes; cálice decíduo, sépalas imbricadas, 5, subiguais ou desiguais; corola rosada ou alva, pétalas imbricadas, 5, iguais ou subiguais; estames livres ou conatos na base, anteras em formato de ferradura, poricidas; ovário unilocular, bicarpelar, óvulos com placentação parietal, estilete terminal, estigma lobado. Fruto cápsula loculicida, bivalvar, com espinhos flexíveis ou inerme, deiscente ou indeiscente. Sementes numerosas, turbinadas, glabras, alaranjadas a vermelhas, testa carnosa.

Bixa possui quatro espécies, com distribuição original na América Tropical, principalmente na região Amazônica (Baer 1976, Lleras 2015). Bixa orellana L., por ser muito cultivada, é provavelmente naturalizada em diversas localidades tropicais (Poppendieck 2002b). No Brasil, ocorrem três espécies de Bixa, nenhuma delas endêmica do país (Antar 2019, Lleras 2015).
Bixa orellana L., Sp. Pl. 1: 512. 1753.

Figura $1 \mathrm{a}-\mathrm{f}$

Árvores a arvoretas até $5 \mathrm{~m}$ de altura. Sistema subterrâneo espessado ausente. Ramos lenticelados, indumento castanho de tricomas peltados, hastados, com diferentes tamanhos de haste, principalmente nos ramos jovens; par de nectários extraflorais circulares presente abaixo da cicatriz estipular. Folhas persistentes, inteiras, membranáceas, ovadas, $8,0-17,0 \times 5,3-10,2 \mathrm{~cm}$, base arredondada, truncada ou cordada, ápice acuminado, margem inteira, indumento constituído de tricomas peltados, não hastados, face adaxial glabra ou com poucos tricomas majoritariamente próximos às nervuras, face abaxial com esparsos tricomas distribuídos em todo o limbo; pecíolo 4,4-6,3 cm compr., com esparsos tricomas peltados, hastados e não hastados; estípulas lineares 1,0-1,5 $\times 1-2 \mathrm{~mm}$, cedo caducas, deixando cicatriz no caule, face adaxial glabra, face abaxial com tricomas peltados, não hastados, densamente dispostos. Inflorescência em panícula, 4.5-10 cm compr., com indumento denso de tricomas peltados, hastados, com 8-13(-20) flores; brácteas cedo caducas, triangulares, 5-8 mm compr., deixando cicatriz no pedicelo. Flores 3-6 cm diâm.; pedicelos 5-8 mm compr.; 5 nectários extraflorais no ápice do pedicelo, circulares, ovais ou de formato irregular; sépalas cedo caducas, largamente ovadas, côncavas, subiguais ou desiguais, $8-10 \mathrm{~mm}$ compr., ápice obtuso, mucronado, base truncada, face abaxial com denso indumento de tricomas peltados, não hastados, face adaxial glabrescente; pétalas rosadas, subiguais, membranáceas, obovadas, glabras, 1,8-2,2 $\times 1,0-1,2 \mathrm{~cm}$, ápice obtuso a arredondado, base cuneada; estames 7-9 mm compr., filetes 5-8 $\mathrm{mm}$ compr., antera ca. $1 \mathrm{~mm}$ compr., com dois 


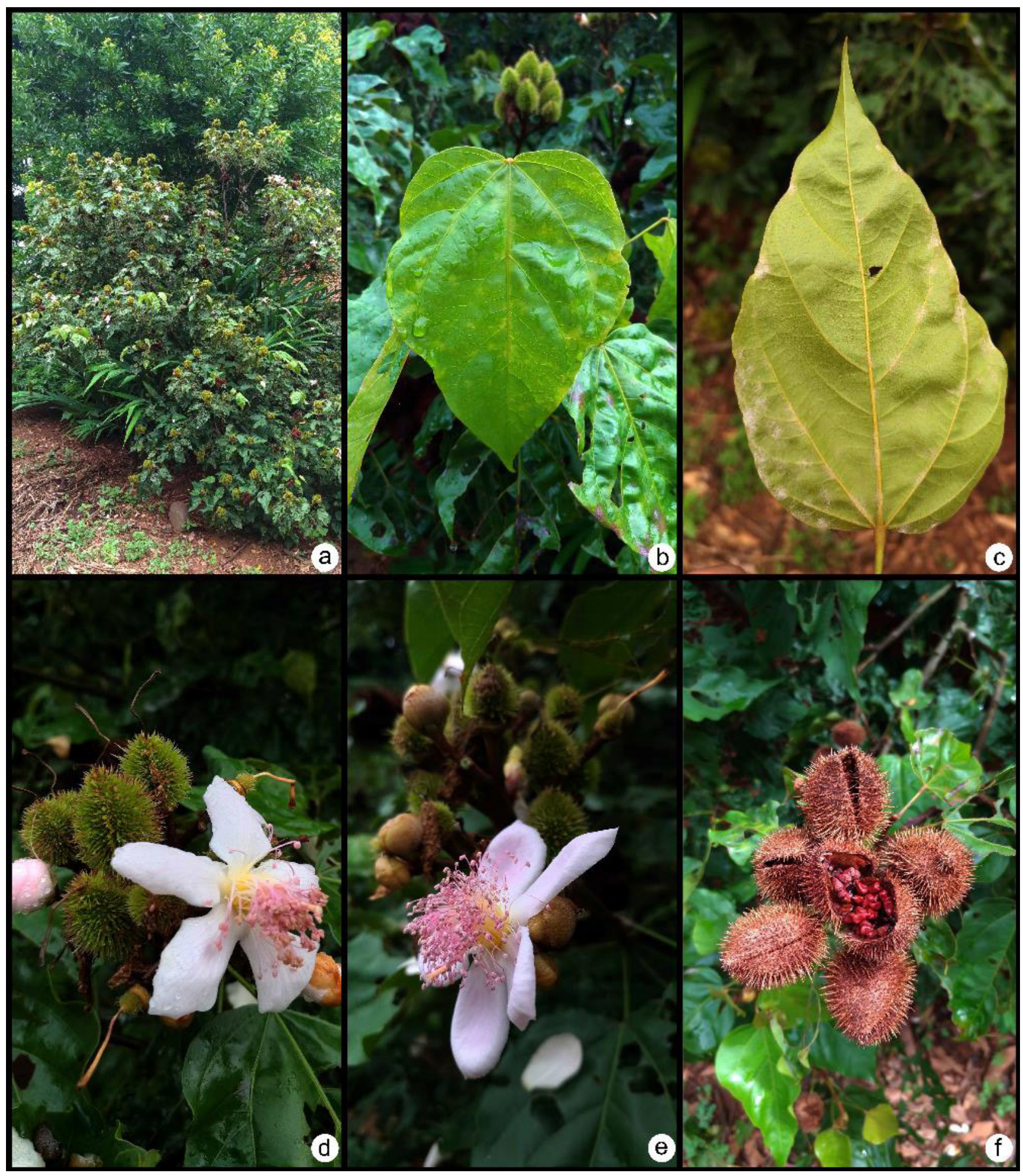

Figura 1. Bixa orellana L. a. Hábito. b. Folha: face adaxial. c. Folha: face abaxial. d. Inflorescência, flor em anteses e frutos jovens, verdes. e. Inflorescência, flor em antese e botões florais. f. Frutos maduros. a-f: fotos de Eduardo Damasceno Lozano.

Figure 1. Bixa orellana L. a. Habit. b. Leaf: adaxial surface. c. Leaf: abaxial surface. d. Inflorescence, flower in anthesis and immature green fruits. e. Inflorescence, flower in anthesis and flower buds. f. Mature fruits. a-f: photos by Eduardo Damasceno Lozano. 
poros lineares no ápice; ovário ovoide a subgloboso, ca. $3 \mathrm{~mm} \times$ ca. $4 \mathrm{~mm}$, densamente coberto por tricomas, estilete ereto na antese, ca. $15 \mathrm{~mm}$ compr., glabro. Fruto cápsula deiscente, verde a vermelha, passando a negra, 3-4 × 2,5-3,5 $\mathrm{cm}$, ovoide a arredondada, ápice acuminado, indumento compostos por tricomas peltados, sésseis ou hastados, espinhos densamente dispostos, 7-12 mm compr.; pedúnculo 1.3-2.2 cm compr., 2-3 mm larg. Sementes turbinadas, avermelhadas, $4-6 \times$ ca. $3 \mathrm{~mm}$, papilosas.

Material selecionado: BRASIL. PARANÁ: Lupionópolis, RPPN Mata São Pedro, 13-IV-2007, fr., T.M. Marestoni 12 (MBM, FUEL). Santa Amélia, Posto Indígena Laranjinha, 3-XII-1992, fl., N.R. Marquesini (MBM202427, UPCB20809).

Distribuição e habitat: Bixa orellana possui ocorrência do sul do México ao sul do Brasil, além da África, Oceania e Ásia (Baer 1976). No Brasil, B. orellana ocorre em todos os Estados e no Distrito Federal, principalmente em áreas com pressão antrópica, mas também em florestas e ambientes de campo ou savana (Antar 2019). A espécie, provavelmente natural do domínio amazônico (Clement et al. 2010), é amplamente cultivada devido a sua importância alimentícia e seu uso como corante natural, sendo conhecida popularmente no Brasil como Urucum ou Coloral (Dequigiovanii et al. 2018). Pelo seu amplo cultivo, é difícil estabelecer os limites da distribuição natural da espécie (Moreira et al. 2015, Dequigiovanii et al. 2018). No Estado do Paraná, é amplamente cultivada com registros principalmente no leste, noroeste e sudoeste do Estado (figura 2).

Fenologia: no Estado do Paraná, foi encontrada com flores em todos os meses, com exceção de fevereiro, agosto e novembro. Foi encontrada em fruto em todos os meses, com exceção de fevereiro.

Nota: Bixa orellana pode ser facilmente reconhecida dentre as outras espécies de Bixa por apresentar porte de arvoreta com até 5 metros de altura, enquanto as outras espécies do gênero são árvores de grande porte, com mais de 10 metros de altura. Além disso, é caracterizada pela presença de nectários extraflorais

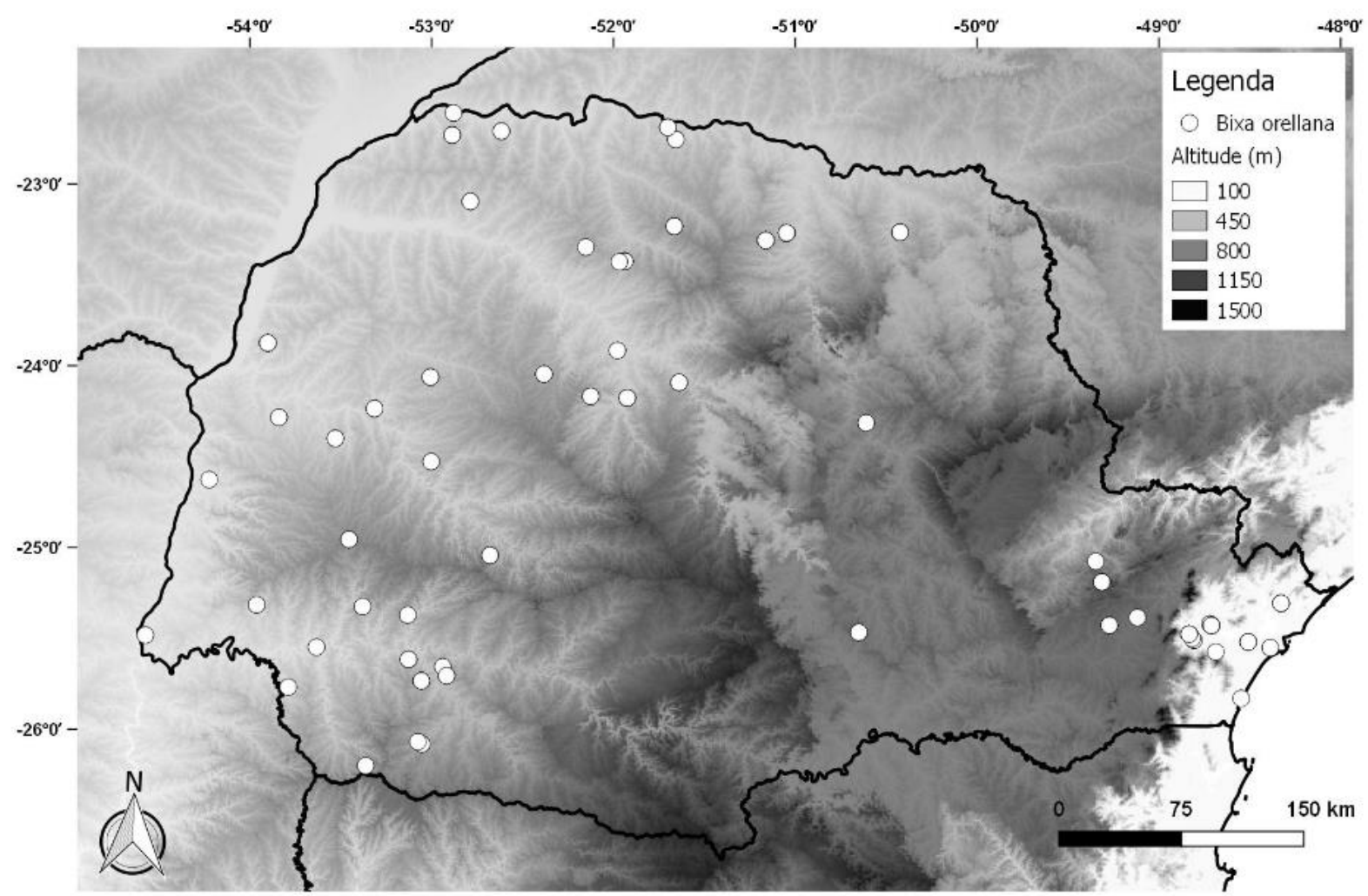

Figura 2. Distribuição de Bixa orellana L. no Estado do Paraná, Brasil.

Figure 2. Distribution of Bixa orellana L. in the state of Paraná, Brazil. 


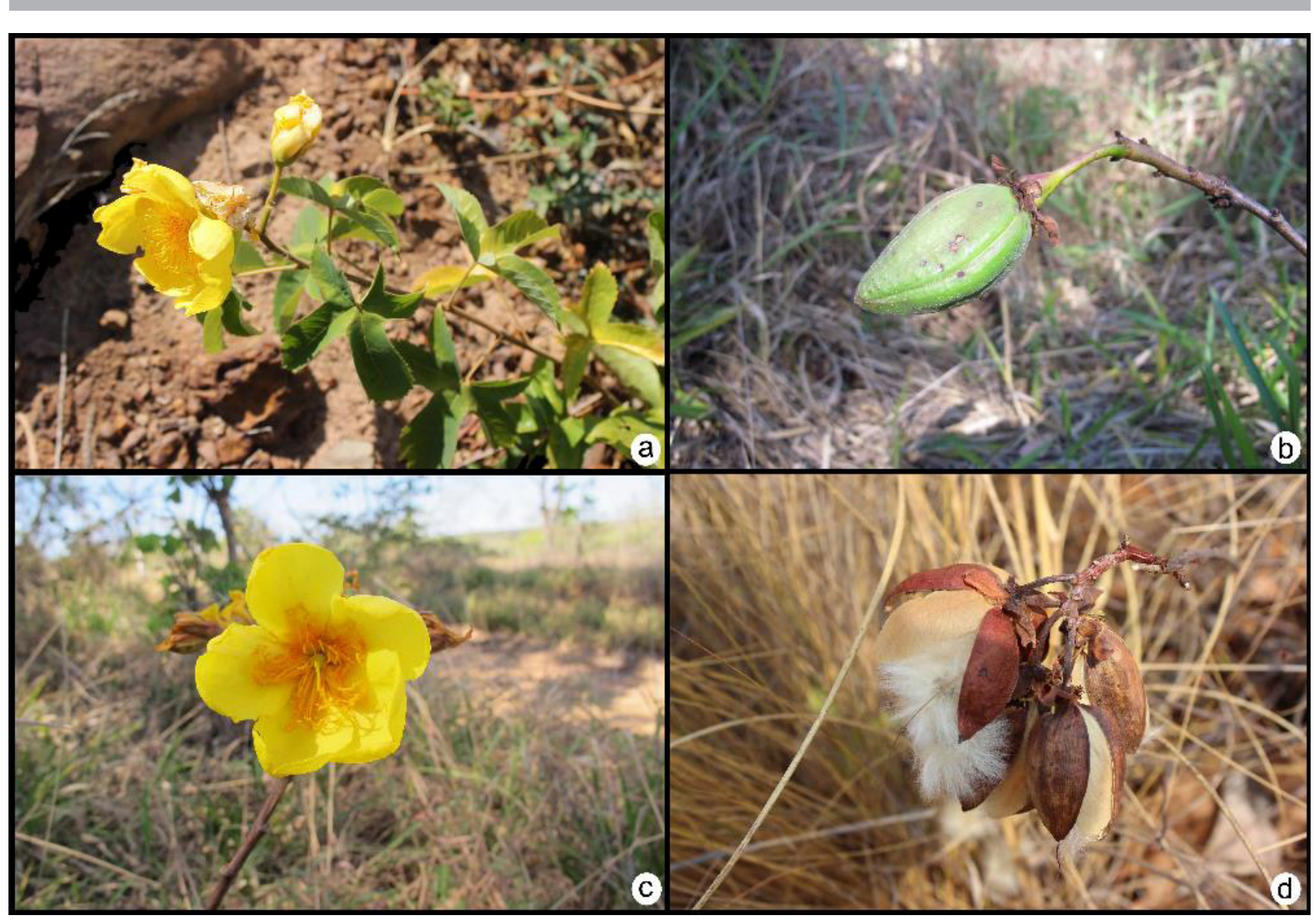

Figura 3. Cochlospermum regium (Mart. ex Schrank) Pilg.. a. Hábito. b. Frutos imaturos. c. Flor. d. Frutos maduros. a-d: fotos de Guilherme Medeiros Antar.

Figure 3. Cochlospermum regium (Mart. ex Schrank) Pilg. a. Habit. b. Immature fruits. c. Flower. d. Mature fruits. a-d: photos by Guilherme Medeiros Antar.

no ápice do pedicelo conspícuos e frutos ovoides a arredondados, não achatados e com espinhos densamente dispostos.

\section{Cochlospermum Kunth}

Árvores, arbustos ou subarbustos; órgão subterrâneo de reserva frequentemente presente, indumento de tricomas simples ou plantas glabras. Folhas compostas e palmadas ou simples e palmatilobadas, com (3)5-9 lobos, frequentemente decíduas durante a floração, margem frequentemente serreada, raramente inteira; estípulas subuladas, decíduas. Inflorescências racemosas ou paniculadas, terminais. Flores actinomorfas; cálice persistente, sépalas 5, desiguais, as duas mais externas menores, as três internas maiores e assimétricas; corola amarela, frequentemente com estrias vermelhas, pétalas 5 , membranáceas, ovadas a obovadas, base cuneada, ápice obtuso, frequentemente emarginado, glabras ou com margem ciliada; estames iguais, anteras estreitas, deiscência poricida, 1-2 poros apicais, 0-2 poros basais; ovário 3-5 carpelar, unilocular, glabro, estilete terminal, curvo ou reto. Fruto cápsula loculicida, deiscente, 3-5 valvar, inerme. Sementes não carnosas, cocleadas ou reniformes, lanosas.

Cochlospermum possui distribuição na América, África, Ásia e Oceania, apresentando aproximadamente 15 espécies (Cowie \& Kerrigan 2015, Johnson-Fulton \& Watson 2017, Poppendieck 1981). Representantes do gênero podem ser encontrados em ambientes abertos ou em florestas estacionais, como também em ambientes antropizados (Poppendieck 2002a).

Estudos filogenéticos indicaram Cochclopermum como parafilético (Johnson-Fulton \& Watson 2017), entretanto, devido ao baixo suporte e à falta de resolução nas filogenias obtidas, decisões nomenclaturais aguardam novas hipóteses sobre esses táxons. 
Cochlospermum regium (Mart. ex Schrank) Pilg., Notizbl. Bot. Gart. Berlim-Dahlem 8: 127. 1924. Figura 3 a-d

Arbustos a subarbustos 0,7-2 m alt. Sistema subterrâneo espessado presente, do qual partem os ramos aéreos. Ramos aéreos jovens vilosos a pubescentes, castanhos, tornando-se glabros e cinéreos, 3-5 mm diâm, nectários extraflorais ausentes. Folhas frequentemente decíduas, 3-5-lobadas, cartáceas, 3,5-8 × 7-10 cm, base cordada; lobos unidos em 10-20\% de seu comprimento, serreados, elíptico-ovados, ápice agudo, faces adaxial e abaxial glabras, glabrescentes ou pilosas nas nervuras e margens, lobos laterais menores que os medianos; lobo mediano 2-4 cm larg.; pecíolos 3,5-7 cm compr., pilosos a glabrescentes; estípulas subuladas $0,5-1,2$ $\mathrm{cm}$ compr., caducas, pubescentes com tricomas concentrados no ápice. Inflorescência em racemo ou panícula, $11-15 \mathrm{~cm}$ compr., pubescente a glabrescente, (1-)3-6(-10) flores por inflorescência; brácteas caducas, triangulares, 3-4 × 0,7-1 mm, cicatriz pouco conspícua. Flores 5-7 cm diâm.; pedicelo 2,0-3,2 cm compr., nectários extraflorais ausentes; sépalas persistentes, elípticas, externas 1,5-2 × 0,6-1,0 cm, internas 2-2,5 $\times 0,9-1,3 \mathrm{~cm}$, ápice agudo, base arredondada, cuneada ou truncada, pubescentes em ambas as faces; pétalas amareladas, subiguais, membranáceas, elípticas, diminutamente ciliadas nas margens ou totalmente glabras, $2,5-4 \times 1,7-2,5 \mathrm{~cm}$, emarginadas no ápice até $3 \mathrm{~mm}$ ou não emarginadas, base cuneada; estames 1,1-2,5 cm compr., filetes 0,8-2 cm compr., anteras 4,0-6,5 mm compr., um poro apical e dois poros basais triangulares; ovário globoso, 3-4 mm diâm., glabro a densamente pubescente, estilete curvado, 1,6-2,0 cm compr., glabrescente com tricomas diminutos. Fruto cápsula deiscente, castanha, geralmente pêndula, 6-7 × 2,3-4,5 cm, oval-elíptica, ápice pubescente, inerme; pedúnculo 2,0-3,5 $\times 2-3 \mathrm{~mm}$. Sementes reniformes, negras, ca. $6 \times 3 \mathrm{~mm}$, tricomas na região dorso-lateral, alvos.

Material selecionado: BRASIL. PARAnÁ: Campo Mourão, Aeroporto, 20-X-1973, fl., G. Hatschbach 32930 (MBM); Lote $7 \mathrm{H}, 2^{\circ} 00^{\prime} 45^{\prime \prime} \mathrm{S} 52^{\circ} 21^{\prime} 52^{\prime \prime} \mathrm{W}$, 12-XI-2013, fr., E.D. Lozano \& E.L. Siqueira 1754 (FLOR, HCF, MBM); sem localidade, 13-X-1965,

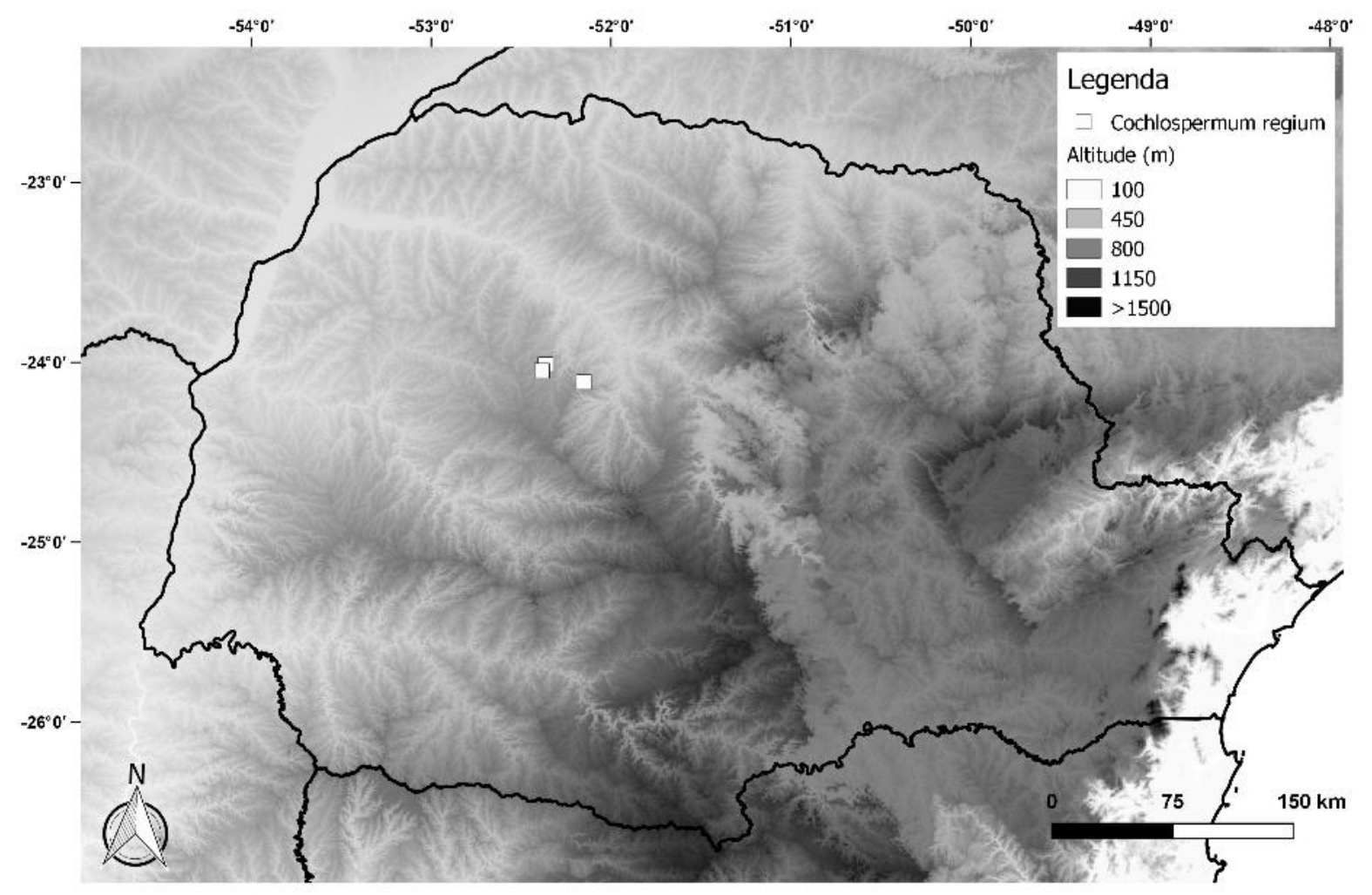

Figura 4. Distribuição de Cochlospermum regium (Mart. ex Schrank) Pilg. no Estado do Paraná, Brasil.

Figure 4. Distribution of Cochlospermum regium (Mart. ex Schrank) Pilg. in the state of Paraná, Brazil. 
fl., G. Hatschbach 12967 (K, MBM); 4-VII-2003, fl., M.G. Caxambu 59 (HCF).

Distribuição e habitat: Cochlospermum regium é nativo do domínio do Cerrado, ocorrendo em fisionomias savânicas e campestres, como também em fisionomias antropizadas (Poppendieck 1981). Ocorre no Brasil, Paraguai e Bolívia (Poppendieck 1981). No Brasil, ocorre em todas as regiões e tem no Estado do Paraná seu limite austral de distribuição, onde possui registros apenas no município de Campo Mourão, localizado na região centro-oeste do Estado (figura 4). A região possui um encrave de Cerrado em meio à matriz de Mata Atlântica. Esta área é notadamente conhecida por possuir espécies com distribuição restrita em todo o Paraná, porém hoje está reduzida a pequenos fragmentos (Hatschbach \& Ziller 1995, Tomadon et al. 2019). Por esse motivo, essa espécie consta como Em Perigo na Lista Vermelha de Plantas Ameaçadas de Extinção no Estado do Paraná (Hatschbach \& Ziller 1995).

Fenologia: foi encontrada com flores de junho a outubro e com frutos em novembro.

Nota: Cochlospermum regium é relacionado morfologicamente a C. vitifolium (Willd.) Spreng., de quem se diferencia pelo hábito arbustivo, com sistema subterrâneo espessado (versus arbóreo ou arbusto maior que 2,5 m), pelos 3-5(7) lobos das folhas (versus 5-7), que são agudos (versus acuminados) e pelo diâmetro das flores, 7-9 cm (versus 8-12 cm).

\section{Considerações finais}

Bixaceae no Paraná está representada por dois gêneros e duas espécies. Bixa orellana apresenta ampla distribuição sendo também cultivada e, dessa maneira, pouco ameaçada quanto a sua conservação. Cochlospermum regium, entretanto, com ocorrência restrita aos remanescentes de Cerrado do Estado, encontra-se sujeita à pressão antrópica, sendo sua principal ameaça, a substituição de ambientes naturais pela agricultura e urbanização (Tomadon et al. 2019). A transformação dos poucos fragmentos restantes de Cerrado da região em Unidades de Conservação, poderia assegurar a manutenção da biodiversidade de espécies do Cerrado no Paraná (Tomadon et al. 2019).

\section{Agradecimentos}

Os autores agradecem à curadoria dos herbários HCF, MBM, RB, SP, SPF e UPCB pela disponibilização de seus acervos. O presente trabalho foi realizado com apoio da Coordenação de Aperfeiçoamento de Pessoal de Nível Superior - Brasil (CAPES) - Código de Financiamento 001; GMA agradece a IdeaWild pelo apoio financeiro. PTS agradece ao CNPq pela bolsa PQ (proc. 310331/2019-6).

\section{Literatura citada}

Alvares, C.A., Stape, J.L., Sentelhas, P.C., Gonçalves, J.L.M. \& Sparovek, G. 2013. Köppen's climate classification map for Brazil. Meteorologische Zeitschrift 22: 711-728.

APG IV (Angiosperm Phylogeny Group). 2016.An update of the Angiosperm Phylogeny Group classification for the orders and families of flowering plants: APG IV. Botanical Journal of the Linnean Society 181: 1-20.

Antar, G.M. 2019. Bixaceae in Flora do Brasil 2020 em construção. Jardim Botânico do Rio de Janeiro. Disponível em http://floradobrasil.jbrj.gov.br/reflora/ floradobrasil/FB27545 (acesso em 30-IV-2019).

Antar, G.M. \& Sano, P.T. 2016. Flora da Serra do Cipó, Minas Gerais: Bixaceae. Boletim de Botânica da Universidade de São Paulo 34: 53-56.

Bayer, C. 2002. Diegodendraceae. In: K. Kubitzki \& C. Bayer (eds.). The families and genera of vascular plants. v. 5. Flowering plants. Dicotyledons. Malvales, Capparales and non-betalain Caryophyllales. Springer. Germany, pp. 175-177.

Cowie, I.D. \& Kerrigan, R.A. 2015. A new species of Cochlospermum (Bixaceae) from Arnhem Land, Northern Territory, Australia. Telopea 18: 135-140.

Dequigiovanni, G., Ramos, S.L.F., Alves-Pereira, A., Fabri, E.G., Picanço-Rodrigues, D., Clement, C.R., Gepts, P. \& Veasey, E.A. 2018. Highly structured genetic diversity of Bixa orellana var. urucurana, the wild ancestor of annatto, in Brazilian Amazonia. Plos One 13: e0198593.

Fay, M.F., Bayer, C., Alverson, W.S., Brujin, A.Y. de \& Chase, M.W. 1998. Plastid rbcl sequence data indicate a close affinity between Diegodendron and Bixa. Taxon 47: 43-50.

Fernandes-Júnior, A.J. \& Gil, A.S.B. 2017. Flora das Cangas da Serra dos Carajás, Pará, Brasil: Bixaceae. Rodriguesia 68: 917-920.

Johnson-Fulton, S.B. \& Watson, L.E. 2017. Phylogenetic Systematics of Cochlospermaceae (Malvales) Based on Molecular and Morphological Evidence. Systematic Botany 42: 271-282.

Harris, J.G. \& Harris, M.W. 2001. Plant identification terminology: an illustrated glossary. Second edition. Spring Lake Publishing, Spring Lake, USA.

Hickey, L.J. 1973. Classification of the architecture of dicotyledonous leaves. American Journal of Botany 60: 17-33. 
Heald, S.V. 2004. Bixaceae. In: N. Smith, S.A. Mori, A. Henderson, D.W. Stevenson \& S.V. Heald (eds.). Flowering Plants of the Neotropics. Princeton University Press, Princeton, pp. 54-55.

Hatschbach, G.G \& Ziller, S.R. 1995. Lista Vermelha de Espécies Ameaçadas de Extinção no estado do Paraná, Curitiba, Secretaria Estadual do Meio ambiente de Curitiba, Biblioteca Nacional do Paraná.

IBGE (Instituto Brasileiro de Geografia e Estatística). 2004. Mapa de Biomas e de Vegetação do Brasil.

Kirizawa, M. \& Abreu, C.T. 2002. Bixaceae. In: M.G.L. Wanderley, G.J. Shepherd \& A.M. Giulietti (eds.). Flora fanerogâmica do Estado de São Paulo. HUCITEC, FAPESP, São Paulo, v. 2, pp. 55-56.

Köppen, W. 1900. Versuch einer Klassifikation der Klimate, vorzugweise nach ihren Beziehungen zur Pflanzenwelt. - Geogr. Z. 6: 657-679.

Poppendieck, H. 1981. Cochlospermaceae. Flora Neotropica Monographs 27: 1-34.

Poppendieck, H. 2002a. Cochlospermaceae. In: K. Kubitzki \& C. Bayer (eds.). The Families and Genera of Vascular Plants. Flowering Plants Dicotyledons Malvales, Capparales and Non-betalain Caryophyllales. v. 5. Springer, Germany, pp. 71-74.

\section{Lista de exsicatas}

Almeida, J.A. s.n. (1.1). Bachi, A. s.n. (1.1). Bonaldi, R. 121 (1.1). Campanini, T.S. s.n. (1.1).

Campiolo, J.B. s.n. (1.1). Carneiro, J.S. 323 (1.1). Carvalho, P.R.R.M. s.n. (1.1). Caxambu, M.G. 59 (2.1). Cervi, A.C. 4062 (1.1). Cielo-Filho, R. 1485 (1.1). Cordeiro, J. 711 (1.1). Cruz, S.R.W.C. 1 (1.1). Dietzmann, P. 1 (1.1). Dunaiski Jr, A. 1242 (1.1). Favaro, S.M. s.n. (1.1). Favro, A. 37 (2.1); 40 (2.1). Ferreira, H.M. s.n. (1.1). Fier, V. 85 (1.1). Figueira, F. s.n. (1.1). Furukawa, E. (1.1). Geraldino, H.C.L. 42 (2.1). Gouvea, M.F. (1.1). Gris, D. 8 (1.1). Hatschbach, G. 12967 (2.1); 32930 (2.1); 36659 (1.1). Hiroki, J. 32
Poppendieck, H. 2002b. Bixaceae. In: K. Kubitzki \& C. Bayer (eds.). The Families and Genera of Vascular Plants. Flowering Plants Dicotyledons Malvales, Capparales and Non-betalain Caryophyllales. v. 5. Springer, Germany, pp. 33-35.

QGIS Development Team. 2019. QGIS Geographic Information System. Beaverton, Oregon: Open Source Geospatial Foundation Project.

Ribeiro, R.T.M. \& Loiola, M.I.B. 2017. Flora do Ceará: Bixaceae. Rodriguésia 68: 1313-1322.

Stevens, P.F. 2019. Angiosperm Phylogeny Website. Version 14, July 2017. Disponível em http://www. mobot.org/MOBOT/research/APweb/ (acesso em 28-III-2019).

Thiers, B. 2019. Index Herbariorum: A global directory of public herbaria and associated staff. New York Botanical Garden's Virtual Herbarium. Disponível em: http:// sweetgum.nybg.org/ih/ (acesso em 30-III-2019).

Tomadon, L.S., Dettke, G.A., Caxambu, M.G., Malfetoni, I.J. \& Couto, E.V. 2019. Significance of forest fragments for conservation of endangered vascular plant species in southern Brazil hotspots. Écoscience.

(1.1). Keller, W.M.T. s.n. (1.1). Lima, J.M. 304 (1.1). Lima, R.X. 282 (1.1). Longhi, S.J. s.n. (1.1). Lozano, E.D. 1754 (2.1). Machado, I. s.n. (1.1). Majolo, C. s.n. (1.1). Marestoni, T.M. 12 (1.1). Marques, L.C. s.n. (1.1). Marquesini, N.R. s.n. (1.1). Milaneze-Gutierre, M.A. 1620 (1.1). Moreira, V.C. (1.1). Morelli, M.M. 11 (1.1). Nakano, E.M. (1.1). Nobre, J.K. s.n. (1.1). Pelisson, A. s.n. (1.1). Santos, M. 17 (1.1). Sekine, E.S. 103 (1.1). Selusniaki, M. 61 (1.1); 254 (1.1). Silva, M.N. s.n. (1.1). Siqueira, E.L. 477 (1.1). Souza, V.A. 1 (1.1). Tanaka, J.T. s.n. (1.1). Vernier, R. 1 (1.1). Wiest, J.M.s.n. (1.1). Wurtzius, A. s.n. (1.1). Ziller, S.R. 852 (1.1); 955 (1.1). Zorzan, M. (1.1). 